\title{
Private information, excessive volatility and intraday empirical regularities in the spot foreign exchange market
}

\author{
Frank McGroarty ${ }^{1}$, Owain ap Gwilym ${ }^{2}$ and Stephen Thomas ${ }^{3}$
}

\begin{abstract}
Financial markets generally, and the spot foreign exchange market in particular, are reputed to be excessively volatile. Previous research has linked this excess volatility to private information. This article re-examines the theory and challenges that link. Empirical evidence suggests that random variation between buy and sell volumes is a more important driver than private information in the spot foreign exchange market. The paper also develops theoretical propositions for the relationships between key market variables on an intraday basis. High frequency data is used to examine the role of private information in explaining well documented intraday patterns that persist in the time series of a number of trade related variables, including return volatility.
\end{abstract}

JEL Classification: F31; G12; G15; D4

Keywords: High frequency data, Foreign exchange, Market microstructure, Asymmetric information, Order-driven.

1 Corresponding author. Lecturer in Finance, School of Management, University of Southampton, SO17 1BJ, UK.

2 Professor of Finance, School of Management \& Business, University of Wales, Aberystwyth, SY23 3DD. UK.

Tel: +44 1970621834 Fax: +44 1970622409 oma@aber.ac.uk

${ }^{3}$ Professor of Financial Markets, School of Management, University of Southampton, SO17 1BJ. UK.

We are very grateful to EBS for supplying the data used in this study.

This version: $3^{\text {rd }}$ February 2005 


\section{Introduction}

Flood and Rose (1995) report that the increase in foreign exchange (FX) rate volatility following the collapse of the Bretton Woods system of fixed exchange rates was not accompanied by a corresponding increase in the volatility of the macroeconomic variables that are believed to drive exchange rates. It is this argument more than any other that gives exchange rates the sobriquet of excessively volatile. French and Roll (1986) forged a link between excessive volatility in the stock market and private information. Their analysis is based on periods of unscheduled closure. Ito, Lyons and Melvin (1998) were presented with an opportunity to study a similar unscheduled closure phenomenon in the FX market. Their conclusion matched that of French and Roll (1986), i.e. that private information must be the catalyst for the observed excessive volatility.

The central focus of the present paper is the link between private information and excessive volatility, but in a different setting. Instead of analysing periods of unscheduled closure, our setting is the trading day. The paper presents a new and unusually rich spot FX dataset of global inter-dealer electronic transactions, which enables us to undertake a fresh empirical investigation of one of the most important puzzles in finance: why are exchange rates reputed to be excessively volatile?

Aside from the central question of private information and excessive volatility, this analysis is important because the spot FX market has previously been underrepresented in the literature on intraday regularities due to difficulties in obtaining data. We examine the widely observed empirical regularities in intraday return volatility, bid-ask spreads and volume, and extend prior literature by investigating intraday order flow. Evans and Lyons (2002) define order flow as "the net of buyer-initiated and seller-initiated orders" and state that "it is a measure of net buying pressure". These authors argue that order flow is driven by (private) information and they provide strong evidence to show that order flow is the proximate driver of price in the spot FX market. Specifically, they show that cumulative order flow is highly correlated with cumulative price change. If order flow is the manifestation of informed trading activity then order flow should have a measurably strong effect on bid-ask spreads. Volume is also widely acknowledged as having close links with bid-ask spreads. 
A general theory which can explain the relationships between the well documented intraday regularities in a variety of trade related variables should be able to shed light on what drives both prices and bid-ask spreads. Many theories have been put forward to explain both the observed phenomena and the relationships between them. The most common theme across these is based on private information. For the first time, we bring this group of theories together and unify them into a coherent and internally-consistent network of hypotheses. In doing so, we find that the impact of informed trading on volatility is misspecified in one of the core models and has subsequently been widely misunderstood. We develop new hypotheses on the relationship between informed trading and volatility. We use a correlation matrix in testing our multiple contemporaneous hypotheses, and examine whether these relationships under investigation have changed since the introduction of the euro. Finally, we reveal the importance of asymmetric information in explaining observed intraday regularities in the four key variables mentioned above.

Understanding intraday regularities is important for market participants, regulators and researchers. It can help traders identify the most/least advantageous times of the day to trade. It is important for policy makers and enforcers to better understand market events, in order to formulate and implement effective regulation. Empiricists also need to take account of seasonal effects, as this can be a source of bias in other analyses.

The remainder of the paper is organised as follows. Section 2 reviews the prior theoretical and empirical literature, and Section 3 draws together the various strands of theory and expounds a set of broad hypotheses about market relationships. Section 4 explains the data and methodology, and Section 5 presents the empirical results. Section 6 concludes.

\section{Literature Review}

\subsection{Theoretical Background}

Two broad sets of theoretical models exist which seek to explain the intraday behaviour of key financial market variables. The first argues that private or asymmetric information is a central factor, as market agents strategically optimise their trading behaviour to minimise trading costs and the market impact of their trades. The second focuses on the role of market structure, suggesting that these patterns are incidental and occur because of longer horizon strategic behaviour of traders. 
The asymmetric information argument can be traced back to Admati and Pfleiderer (1988) who extend Kyle's (1984) model to explain intraday phenomena. Their central argument is that volume patterns emerge because informed and uninformed traders choose to trade at the same time in order to minimise transactions costs. Rejecting the Admati and Pfleiderer (1988) explanation as insufficient to fully explain empirical observations, Brock and Kleidon (1992) make the case that traders have different optimal holding portfolios when the market is closed from when the market is open. They argue that volumes are larger at the open and close because of portfolio rebalancing. While the Admati and Pfleiderer (1988) and Brock and Kleidon (1992) models focus on different explanations of volume, it is important to note that their predictions do not entirely contradict each other. It is possible that the drivers identified in both models could combine in the overall result.

Brock and Kleidon (1992) predict a U-shaped intra-day pattern in bid-ask spreads if market makers have some degree of monopoly power. They argue that this is a natural response to increased order flow at the open and close. More precisely, they argue that it is two different natural responses. At the open, market makers maintain wide bid-ask spreads because they fear they could be adversely selected by traders who know more than they do, before they can get a firm estimate of the true price level. At the close, they maintain wide bid-ask spreads in an attempt to avoid exposing themselves to the risk of holding unwanted inventory positions over the closed period. The monopoly power assumption is necessary because in a perfectly competitive market, market makers would always compete the bidask spread down to the minimum level.

Admati and Pfleiderer (1988) address the issue of transaction costs indirectly, in the form of the Kyle- $\lambda$, which measures market makers' price sensitivity (i.e. aversion) to order flow. Their model shows that the Kyle- $\lambda$ is expected to be lower at times of high volume. It could be interpreted from this that market makers will put up bid-ask spreads when they are more averse to order flow but Admati and Pfleiderer (1988) do not make this explicit. Kyle (1984) defines $\lambda$ as the inverse of market depth. Empirical work by Lee et al (1993), Ahn et al (1999) and Danielsson and Payne (2001) demonstrate that bid-ask spreads and depth are negatively related. While other literature (e.g. Harris (1994), Goldstein and Kavajecz (2000) and Jones and Lipson (2001)) reports that narrower spreads coincide with less depth, those findings all relate to markets in which the price resolution or minimum tick size has 
changed. Absent such changes in price granularity, the evidence indicates that the Kyle- $\lambda$ should be positively related to bid-ask spreads, which implies that the bid-ask spread should narrow as volume rises. For markets that close overnight, this means that a U-shaped volume pattern should be accompanied by an inverted-U-shaped bid-ask spread pattern. Brock and Kleidon (1992) take issue with the latter prediction because it does not match empirical observations. Bid-ask spreads are consistently observed to be U-shaped over the trading day, not inverted-U-shaped.

Subrahmanyam (1991) extends the Admati and Pfleiderer (1988) model by allowing informed traders, who had been risk neutral, to become risk averse and so, enables high volumes and wide bid-ask spreads to co-exist. However, in so doing, the motivation for volume to concentrate at certain times of day (a central argument of the Admati and Pfleiderer (1988) model) is lost. This happens because risk averse informed traders would trade more during high volume periods than risk neutral informed traders. Increased informed trading increases adverse selection risk causing high volume trading costs to rise, with the result that discretionary liquidity traders no longer wish to trade alongside informed traders.

The conventional measure of return in intraday market microstructure studies is price change volatility or, more precisely, the across-day variance of successive price changes over each time segment. This volatility measure concentrates on the magnitude of returns associated with a particular time of day because price changes can be both positive and negative. Thus, high return volatility in a particular time segment reveals the presence of extreme price moves at that time of day. Admati and Pfleiderer (1988) make the case that as informed trading kicks in, price change (i.e. volatility) rises. Subsequently, most empirical researchers ascribe to the Admati and Pfleiderer (1988) model that volume and volatility move in the same direction. However, as we discuss in detail below, this interpretation of their model is questionable.

Other researchers contend that private information explains the observed relationship of volume and volatility. Copeland (1976) and Jennings, Starks and Fellingham (1981) develop models based on sequential information arrival. Here, an individual trader receives a signal ahead of the market and trades on it, thereby creating volume and moving price (i.e. creating volatility). Hence, volatility and volume move in the same direction. 
French and Roll (1986) consider three alternative explanations for the observed positive relationship between volume and volatility: (1) Relevant public announcements are made primarily during trading hours and so affect price at that time; (2) errors in pricing rise linearly with volume; and (3) some traders may be trading on private information which is either not available or can not be exploited in quiet times. By ruling out the first two explanations, they conclude that informed trading must be the source of the excess volatility they observed in the periods when the market was continuously open. Ito, Lyons and Melvin (1998) applied this model to the Tokyo spot FX market over a period during which a ban on lunchtime trading was lifted. Echoing French and Roll (1986), they found that volatility doubled when trading was permitted at lunchtime.

While Brock and Kleidon (1992) do not focus on volatility, other researchers use nonprivate information arguments to explain why volatility is observed to have the same intraday pattern as volume. The main theory here is Clark's (1973) Mixture of Distributions Hypothesis $(\mathrm{MDH})$, which argues that volatility and volume move together in response to a common unobservable external stimulus, deemed to be information flow. The arrival of news pushes both volume and volatility (a measure of absolute price adjustment) in the same direction. Later researchers have elaborated on this idea. Epps and Epps (1976) link intraday volatility to disparate opinions among traders following a price signal. Tauchen and Pitts (1983) develop the disparate opinion among traders model more formally. They propose a bivariate mixture model in which volume and price change are jointly distributed due to the presence of a latent variable. This model shows the covariance between volume and price change as zero, while the covariance between volume and price change volatility is positive, which is what has been commonly observed empirically.

Other models based on private information, which relate the bid-ask spread to volume and volatility, exist outside of the specifically intraday pattern models. A significant contribution by Easley and O'Hara (1992) suggests that volume is in itself important for price and bid-ask spread determination. In their words: "absent abnormal volume, prices do not move". Their central message is that "no-trades" convey information too, in that an information event should be followed by a trade. The absence of trades conveys to market makers that an information event has probably not occurred, thereby decreasing adverse selection risk. This in turn should decrease the bid-ask spread. The upshot of this argument 
is that unanticipated volume, which monotonically reveals the level of informed trading, should be positively correlated with the bid-ask spread. According to Cornell (1978), anticipated volume should be negatively related to the bid-ask spread because of economies of scales, competition among market makers and inventory management opportunities.

An important factor that we utilise below is order flow or, more specifically, the across-day volatility of order flow. Order flow is defined as buyer volume minus seller volume. We were unable to find any theoretical literature which addressed intraday order flow directly.

One feature to be borne in mind is that most of the above models are based in markets which can be modelled in the Kyle $(1984,1985)$ tradition. Specifically, designated market makers are involved in the price setting and bid-ask spread setting processes. However, under electronic order driven systems, there are no designated market makers. Any trader can choose to execute his trade via a limit or a market order. As a result, price and bid-ask spread behaviour may be very different. However, for the purposes of exposition, we continue to use the term "market maker" throughout this paper. For the moment, in the context of order driven markets, we define the term as "the abstract, nebulous means by which liquidity is provided to the market". This function should still cause bid-ask spreads to widen when there is a risk of adverse selection. However, inventory imbalances should be less of a problem. Furthermore, if informed traders can choose between market orders and limit orders, and do so in response to environmental conditions, it may be difficult to distinguish buys from sells in the ex-post order flow. Although the trader does not switch between being a buyer or a seller, it is the behaviour of the aggressor in a trade that determines whether the trade is a buy or a sell. This problem could make any model which is reliant on signed order flow difficult to evaluate.

Models specified on order driven markets are important for the present study because the dataset under analysis derives from an order driven regime. Although there is a general dearth of theoretical research devoted to order driven markets, a number of important papers have emerged. Glosten (1994) develops a model where limit order traders are uninformed and risk-neutral. Market order traders are comprised of both risk-neutral uninformed traders and risk-averse informed traders. He finds that the bid-ask spread is positively related to the level of informed trading because large orders are more likely to come from informed traders. Harris (1998) examines order placement in a variety of market conditions and finds 
that informed traders' preference for market over limit orders is positively related to volume and negatively related to bid-ask spreads. Foucault (1999) presents a sequential, dynamic, one-period model of limit and market order placement in which market participants have diverse opinions about asset valuations. He finds that the propensity to place market rather than limit orders decreases with volatility. However, in volatile periods, many of these limit orders arrive at uncompetitive prices, resulting in a high proportion of these being unfilled. He also finds that bid-ask spreads are positively related to volatility.

In summary, there are different but not always contradictory theories for observed intraday volume patterns. On the one hand, it may be the case that traders rebalance their portfolio when switching between different market states, e.g. open and closed. On the other hand, the observed patterns may result from informed and uninformed traders trading alongside each other. Intraday bid-ask spread patterns may arise because market makers exercise monopoly power in the face of higher volumes. Alternatively, bid-ask spreads may widen in response to unanticipated volumes and fall in response to anticipated volumes. Price change volatility may be positively related to informed trading or it may be linked to disagreement between traders about the true price. Unanticipated volume is associated with informed trading, as is volatility, but in different ways. The market making function is very different in order-driven markets, compared with quote driven ones. Most notably, traders can switch from the market side to the limit side of an order without switching their buy or sell intention. Recent work has shown that bid-ask spreads should still widen in response to informed trading under order driven regimes and also that bid-ask spreads should still widen with volatility. In addition, theorists have found that both high volatility and wide bid-ask spreads lead informed traders to choose limit orders over market orders, whereas high volume has the opposite effect.

\subsection{Previous Empirical Evidence}

An overwhelming number of empirical papers have documented U-shaped patterns in intraday data for a wide range of variables. A U-shaped intraday pattern in bid-ask spreads is found in futures markets by Ma et al (1992), Wang et al (1994), Abhyankar et al (1995), and Ding (1999). In contrast, Franses et al (1997) find a flat distribution of bid-ask spreads across the day for the LIFFE Bund future. U-shaped intraday equity bid-ask spreads are reported by McInish and Wood (1992), Brock and Kleidon (1992), Lee et al (1993), 
Lehmann and Modest (1994), Chan, Chung and Johnson (1995), Werner and Kleidon (1996), Abhyankar et al (1997), Brockman and Chung (1998), Ahn et al (1999), Levin and Wright (1999) and Madhavan et al (1997). Shifting the focus to order driven markets, Chan, Christie and Schultz (1995) find that Nasdaq bid-ask spreads are flat throughout the day and tail off significantly at the close. Danielsson and Payne (2001) find a W-shaped pattern in USD/DEM bid-ask spreads for the 24-hour inter-dealer spot FX market.

Many studies address the issue of intraday volumes or number of trades. Ekman (1992) and DeJong and Donders (1998) find a U-shaped intraday pattern in the number of trades in futures markets. A U-shaped intraday volume pattern is found in futures markets by Gannon (1994), Abhyankar et al (1995), ap Gwilym et al (1996), Franses et al (1997), Buckle et al (1998), Piccinato et al (1998) and Tse (1999). A U-shaped intraday pattern in equity volumes is reported by Jain and Joh (1988), McInish and Wood (1990), Stephan and Whaley (1990), Gerety and Mulherin (1992), Foster and Viswanathan (1993), Lee et al (1993), Niemeyer and Sandas (1993), Lehmann and Modest (1994), Atkins and Basu (1995), Chan, Chung and Johnson (1995), Werner and Kleidon (1996), and Madhavan et al (1997). Abhyankar et al (1997) find an M-shaped volume pattern for UK stocks. In relation to order driven markets, U-shaped intraday volume is reported by Chan, Christie and Schultz (1995) for Nasdaq stocks. Danielsson and Payne (2001) find an M-shaped volume pattern for USD/DEM spot exchange rate on Reuters global inter-dealer FX trading platform.

Researchers have found compelling empirical evidence of the same U-shaped pattern in the intraday volatility of price changes. This is reported in futures markets by Kawaller et al (1990), Froot et al (1990), Cheung and Ng (1990), Chan et al (1991), Ekman (1992), Ito and Lin (1992), Becker et al (1993), Gannon (1994), Lee and Linn (1994), Wang et al (1994), Chang et al (1995), Daigler (1997), Franses et al (1997), Kofman and Martens (1997), Buckle et al (1998), and Tse (1999). U-shaped intraday volatility in equity markets is reported by McInish and Wood (1990), Gerety and Mulherin (1992), Lehmann and Modest (1994), Werner and Kleidon (1996) and Abhyankar et al (1997). In order driven markets, Andersen and Bollerslev (1997) found a W-shaped pattern for S\&P 500 futures. Hiraki et al (1995) found a reverse L shape for the Nikkei futures. Chan, Christie and Schultz (1995) find the U-shaped volume on Nasdaq. In the spot FX market, Baillie and Bollerslev (1990) find that volatility for the major currency pairs peaks twice during the day, when London 
and New York open, yielding an M-shaped plot. Low and Muthuswamy (1996) find similar peaks in price change volatility for three major currency pairs when London and New York open and close. Hseih and Kleidon (1996) and Docking et al (1999) find the same result for the USD/DEM.

Like the theoretical literature, the intraday empirical literature neglects the role of order flow. With the notable exception of the spot foreign exchange examples, the predominant finding from the empirical literature is that bid-ask spreads, volumes and price change volatility all exhibit a U-shaped intraday pattern. Both bid-ask spreads and volumes appear to rise at the open and the close of the market. Such patterns might not be found in the present study. The spot FX data utilized is from a 24-hour global market and so does not have an open or close per se. Although peaks may coincide with the London/New York open/close, it is anticipated that the specific prior spot FX findings will be more relevant to our analysis than the commonly reported U-shaped observations.

Bessembinder (1994) and Jorion (1996) test the idea that expected and unexpected volume affect bid-ask spreads in opposite ways, using data on FX futures. Hartmann (1998) tests the same relationships on inter-dealer spot USD/JPY volumes. Danielsson and Payne (2001) apply the expected-unexpected split to high-frequency inter-dealer spot USD/DEM volumes. All find evidence supporting the Easley and O’Hara (1992) argument.

\section{A Unified Theoretical Framework}

The theoretical approach underlying the analysis that follows is based on the asymmetric information explanation for intraday empirical regularities. The Brock and Kleidon (1992) approach would not be appropriate for analysing the spot FX market because this market is 24-hour/global and therefore does not have daily open and close events per se. Consequently, the initial premise that these researchers tackle, the U-shaped pattern, does not exist in this market (see Danielsson and Payne (2001)). The latter paper also documents that bid-ask spreads and volumes have opposing patterns, while their patterns are usually aligned in other financial markets.

Another justification for concentrating on asymmetric information rather than the market structure argument is that inventory risk is observed to be generally much lower in the spot 
FX markets compared with the more widely studied equity markets. Lyons (2001) witnessed that a "large bank dealer in the USD/DEM market that [he] tracked in 1992 finished his trading day with no net position within each of the five days in the sample, despite trading over $\$ 1$ billion each day. Within the day, the half-life of the gap between his current position and zero was only ten minutes". In contrast, Hasbrouck and Sofianos (1993) and Madhavan and Smidt (1993) find that it takes NYSE specialists a week to achieve the same outcome. For reasons discussed above, the inventory factor should be less important under order-driven regimes.

Drawing together the various strands of theory, but with particular emphasis on Admati and Pfleiderer (1988), we form a number of hypotheses set out below. In doing this, an issue was identified with Admati and Pfleiderer's (1988) volume-volatility relationship. Much empirical work which draws on this theory ascribes a positive volume-volatility relationship to it. However, Admati and Pfleiderer (1988) actually state the following about price change volatility: (a) it rises at the transition point when informed trading volume kicks in; (b) it falls at the transition point when informed trading subsides; and (c) it is constant everywhere else. In their own words, "when the number of informed traders is greater in the later period, [price change volatility rises]. This is because more information is revealed in the later period than in the earlier one. When the number of informed traders decreases from one period to the next, [price change volatility falls], since more information is revealed in the earlier period". Their conclusion on the non-transition trading periods is revealed in Proposition 3, where they state that, “...the variance of price changes is the same when $n$ informed traders trade in each period as it is when there is no informed trading.....With some informed traders, the market gets information earlier than it otherwise would, but the overall rate at which information comes to the market is unchanged."

However, this idea that order flow has no impact on price change volatility just because it does not reduce the total amount of information is flawed. It is only true if foresight is both perfect and free, which these authors do not assume. Indeed, such an assumption would be inconsistent with any variation in the number of informed traders which is central to their model. At the core of this issue, is the conceptual relationship between order flow and the price change process. Admati and Pfleiderer (1988) define their price innovation process as a martingale. Therefore, it follows that successive price innovations can have opposing signs. This allows order flow to counteract the prevailing price innovation and reduce the 
price change. As we illustrate below, the relationship between volume and volatility actually implied by this model, turns out to be the opposite of that usually inferred.

Admati and Pfleiderer (1988) use the price generating process from Kyle (1984):

$P_{t}=P_{0}+\sum_{\tau=1}^{t} \delta_{\tau}+\lambda_{t} \omega_{t}$

\section{Equation 1: The Kyle price formation equation}

The current price, $P_{t}$ is made up of a starting value $P_{0}$, the sum of price innovations, $\delta$, since the start and current order flow, $\omega_{t}$, multiplied by a coefficient, $\lambda$, which reflects market maker aversion to order flow. $\lambda$ is always positive. Order flow is driven by private information about the next price innovation $\delta_{t+1}$, and also by the expected transaction cost, given by $\lambda$. Price changes in this model are defined as:

$R_{t}=P_{t}-P_{t-1}=\delta_{t}-\lambda_{t-1} \omega_{t-1}+\lambda_{t} \omega_{t}$

\section{Equation 2: Price changes in the Kyle model}

In this price change definition, the first component of the price change, $\delta$, is the price innovation for the current trading period. The second term captures earlier price movement caused by prior predictions of $\delta$. These two terms together comprise the residual or unexploited current price innovation. The last term is a price disturbance predicting the next price innovation.

The Kyle (1984) framework contains an implicit relationship, which is important for understanding the relationship between volume and price change volatility - price change does not simply depend on either $\lambda$ or $\omega$, but, rather, on how these two interact. For a given price signal, $\lambda$ and $\omega$ are solely and inversely determined by the expected value of the other. If $\lambda$ is anticipated to rise, $\omega$ should fall, such that just enough $\omega$ is put through to exhaust the price signal. If increased volume should cause the general level of $\omega$ to rise, it is accompanied by a fall in $\lambda$, such that no more than the price signal feeds through to price change. If each fully anticipates the other, then any point, $\lambda \omega$, on the curve in Figure 1 will fully exhaust the price signal and fully convey it to price change. Given this, the focus shifts 
to how informative the price signal actually is. If the price signal carries no information then $\omega$ is zero and price change volatility is simply the variance of $\delta, \operatorname{var}(\delta)$. At the other extreme, if foresight is perfect and costless, then, for any given $\lambda$, order flow rises to fully capture each price innovation. This causes the first two terms in the price change equation above to cancel out and the third term to equal $\delta_{t+1}$. In other words, the price innovation is shifted in time by one period and price change volatility is again $\operatorname{var}(\delta)$. However, $\operatorname{var}(\delta)$ is only preserved in these extremes. As the following equation shows, order flow will erode $\operatorname{var}(\delta)$ at all intermediate points:

$\sigma_{r}^{2}=\sigma_{\delta_{t}-\lambda_{t-1} \omega_{t-1}}^{2}+\sigma_{\lambda_{t} \omega_{t}}^{2}+2 \rho_{\delta_{t}-\lambda_{t-1} \omega_{t-1}, \lambda_{t} \omega_{t}} \sigma_{\delta_{t}-\lambda_{t-1} \omega_{t-1}} \sigma_{\lambda_{t} \omega_{t}}$ $=(1-\varphi)^{2} \sigma_{\delta_{t}}^{2}+\varphi^{2} \sigma_{\delta_{t+1}}^{2}+2 \varphi(1-\varphi) \rho_{\delta_{t}, \delta_{t+1}} \sigma_{\delta_{t}} \sigma_{\delta_{t+1}}$

where

$\sigma_{r}^{2}=$ Return volatility

$\sigma_{\delta_{t}-\lambda_{t-1} \omega_{t-1}}^{2}=$ Variance of unexploited $\delta_{t}$

$\sigma_{\lambda_{t} \omega_{t}}^{2}=$ Variance of $\lambda_{t} \omega_{t}$ (= forecast part of $\delta_{t+1}$ )

$\rho_{\delta_{t}-\lambda \omega_{t-1}, \lambda \omega_{t}}=$ Correlation between unexploited $\delta_{t}$ and $\lambda_{t} \omega_{t}$

$\varphi=$ Percentage of $\delta_{t+1}$ revealed by $\omega_{t}$

$\sigma_{\delta_{t}}^{2}=\sigma_{\delta_{t+1}}^{2}=$ Variance of $\delta$

$\rho_{\delta_{t}, \delta_{t+1}}=1$ st order autocorrelation of $\delta$

Equation 3: Price change volatility with informed trading in the Kyle model

This equation shows that price change volatility is composed of the residual, or unexploited, component of $\delta_{t}(=\delta-\lambda \omega)$, the forecast part of $\delta_{t+1}(=\lambda \omega)$, plus the interaction between the two. Since $\lambda$ is constant within each regime, the variance of the forecast part of $\delta_{t+1}$ can also be modelled as the forecast part of the variance, where $\varphi$ is the portion of $\delta_{t+1}$ revealed by $\omega_{t}$. This relationship is exposed in the following identity:

$$
\sigma_{\lambda_{t} \omega_{t}}^{2} \equiv \sigma_{\varphi \delta_{t+1}}^{2} \equiv \varphi^{2} \sigma_{\delta_{t+1}}^{2}
$$

Equation 4: The variance of the part of $\delta_{t+1}$ revealed at time $t$ by informed trading

Similarly, the residual part of the variance can be modelled as $(1-\varphi)^{2} \sigma_{\delta_{t}}^{2}$. This form of the equation reveals that the interaction part depends on the first order autocorrelation of the $\delta$ 
time series, $\rho_{\delta_{t}, \delta_{t+1}}$. However, Admati and Pfleiderer (1988) assume that $\delta$ is independent and identically distributed (IID). In other words, under Admati and Pfleiderer's (1988) assumptions, price change volatility is:

$\sigma^{2}=\sigma_{\delta-\lambda \omega}^{2}+\sigma_{\lambda \omega}^{2}$ $=(1-\varphi)^{2} \sigma_{\delta_{t}}^{2}+\varphi^{2} \sigma_{\delta_{t+1}}^{2}$

Equation 5: Admati and Pfleiderer (1988) assume $\rho_{\delta_{t}, \delta_{t+1}}$ is 0 .

In an example where the price signal captures $50 \%$ of the next price innovation (i.e. $\varphi=0.5$ ), order flow will erode $50 \%$ of the current price innovation, thus reducing that component of price change volatility. However, contemporaneous order flow relating to $\delta_{t+1}$ provides an additional source of price change volatility. As these two are uncorrelated, there is no interaction component in the aggregate price change. If $\operatorname{var}(\delta)$ is equal to 1 , price change volatility will equal $0.5^{2}$, from the unforecast part of $\delta_{t}$, plus $0.5^{2}$, from the forecast part of $\delta_{t+1}$, which together sum to 0.5 . In fact, in the absence of autocorrelation, $50 \%$ price informativeness produces the minimum possible price change volatility of $\operatorname{var}\left(1 \frac{1}{2} \delta\right)$. All other levels of informativeness nudge price change volatility towards one of the extremes of no information or full information, where it reverts to $\operatorname{var}(\delta)$. Figure 2 presents a visual representation of this example.

Figures 3 and 4 also help to convey the intuition at the heart of this issue. They depict a stylised framework where successive price moves are perfectly negatively correlated. Figure 3 shows how price evolves over time as successively good and bad news is released about an asset. Price is revised up, then down, then back up, etc. in response to each of these news events. This scenario assumes no informed trading activity. Figure 4 considers the same situation with informed trading. The central insight from this figure is that for private information to have any real meaning, it must be linked to a future public information event. The early release of price pressure in period $t$ not only takes away price pressure from period $t+1$, but also counteracts an opposite price action in period $t$.

Admati and Pfleiderer (1988) introduce the assumptions of a fixed information acquisition cost and only two states for $\lambda$. $\lambda$ is assumed to be low during high volume periods and high during low volume periods. Information is now only acquired when it can be fully 
exploited, i.e. when $\lambda$ is low. So, when $\lambda$ is high, $\omega$ should go to zero and price change volatility reverts to $\operatorname{var}(\delta)$. In the model, the latter should happen during low volume trading periods. Since foresight is not assumed to be perfect, price change volatility should fall below $\operatorname{var}(\delta)$ when informed traders are active. Even if foresight is perfect, the cost of information acquisition will require that informed traders make a profit, in which case they will not fully exhaust the price signal, again indicating that price change volatility should be below $\operatorname{var}(\delta)$. In reality, it is hard to envisage circumstances where price would consistently convey more than $50 \%$ of $\delta_{t+1}$. As such, the negative volume-volatility relationship described by the left half of the curve in Figure 2 seems far more plausible than the positive one described by the right hand half. In any case, in the Admati and Pfleiderer(1988) model, informed traders are only active during high volume trading periods. Therefore, price change volatility is the full $\operatorname{var}(\delta)$ in the low volume period and should fall when volume rises. This contradicts both the conclusion reached by Admati and Pfleiderer (1988) and the assertions of empiricists drawing on their work. We adopt the expectation of a negative relationship between volume and volatility in the hypotheses below.

This negative volume-volatility prediction is controversial. It goes beyond just reinterpreting Admati and Pfleiderer (1988). It rejects the volume-volatility predictions of Copeland (1976) and Jennings et al (1981). However, the central point of those two papers was to show that sequential information arrival encompasses volume (= order flow) in the same direction as the price change, as part of the change process. This compares with the alternative tâtonnement process which requires no volume in order to revise price. Neither paper gives any consideration to how a future price innovation would be affected by having information about it released early, which is the key to our argument. The negative volumevolatility conclusion has another important implication. It implies that informed trading is not the additional source of exogenous volatility that French and Roll (1986) had argued. Instead, it suggests that informed trading serves to reduce exogenous volatility by dispersing and mixing price reactions to news.

The Easley and O'Hara (1992) theory poses no opposition to the negative volume-volatility prediction. Their main conclusion on the relationship between volume and price changes is that, in the absence of informed trading and unusual volumes, price change is equal to $\delta t$. However, unusual volume, whether motivated by information or not, will disturb price 
changes. They further show that price will move in the direction of whichever quote is hit. So, if an informed trader finds out that the next price innovation is downwards and initiates a sell order now, the current price will be driven down by his order flow. This will close the gap between the price now and that predicted at the end of the next trading period, reducing the price change, as predicted above.

It is clear from the preceding paragraphs that order flow, $\omega$, is a very important factor in determining both price changes and price change volatility. As a result we include intraday order flow in this investigation. Taking a lead from Hartmann (1998), we utilise an order flow volatility measure. The volatility measure of order flow has the benefit of neatly getting around the signed order flow problem in order driven markets that was identified earlier. The most obvious question is, how should order flow volatility and price change volatility be related? As Figure 1 shows, if $\lambda$ is correctly anticipated, the relationship between order flow and price change depends solely on the average information content of the price signal. As the above discussion shows, the relationship between their variances is similarly dependent on this information content. However, since information is assumed to carry a fixed cost, $\omega$ should be absent when $\lambda$ is high, i.e. when volume is low. In the Admati and Pfleiderer (1988) framework, order flow is the result of informed trading activity and so order flow volatility is positively linked to volume.

In the process of trying to reconcile the conclusions of the various theoretical papers with each other, a deep-rooted apparent inconsistency came to light. This time it was between the Admati and Pfleiderer (1988), and Easley and O'Hara (1992) and relates to their respective conclusions on the bid-ask spread-volume relationship. Admati and Pfleiderer (1988) state that bid-ask spreads should fall as volume rises, partly because much of the volume increase will be uninformed and partly because informed traders compete with each other. Easley and O'Hara (1992) say that bid-ask spreads should rise as volume rises because volume is inversely related to the number of no-trade events. The last point appears tautological but it is not. It says that if there is no volume, there can not be any informed volume. Hence, market makers can not be adversely selected. Conversely, adverse selection risk must rise linearly with volume. Adapting Easley and O'Hara (1992) to the intraday case means that the excess or absence of volume, relative to what is normal at that time of day, indicates the strength or weakness of a price signal. Therefore, bid-ask spreads should rise when volume is relatively high and fall when it is relatively low. 
The Admati and Pfleiderer (1988) framework does not cater for this kind of variation in the price signal. Their focus is purely on when traders should choose to dispatch trades, given inter-temporal bid-ask spreads and constantly available price signals. The conflict can be resolved, while preserving the insights of both models, by recasting volume into two parts, expected and unexpected. This refinement means that market makers should now narrow their bid-ask spreads in high volume periods partly because they expect a high number of informed traders. But competition among these informed traders erodes the adverse selection risk that each one would pose if acting alone. To put it another way, market makers find informed traders more tolerable in high volume periods because they are accompanied by high uninformed volumes and competition among informed traders makes their order flow less damaging. Now, in both high and low volume regimes, where trading deviates from the expected level, variations in the price signal can be inferred and bid-ask spreads can widen or narrow as Easley and O'Hara (1992) predict. A hypothesised negative relationship between bid-ask spreads and expected volume supports Admati and Pfleiderer (1988). The Easley and O'Hara (1992) expectation is manifested in the hypothesis that bidask spreads and unexpected volume are positively related. Expected volume and unexpected volume should be unrelated to each other.

In order to preserve the relationships established previously within a coherent structure, it is also necessary to split order flow volatility into expected and unexpected. Expected order flow volatility should be closely and positively aligned with expected volume, since order flow should be highest during high volume periods. These two should be negatively related to price change volatility. This follows directly from the discussion of the volume-volatility relationship above, since the Admati and Pfleiderer (1988) model did not allow for variations in the price signal. Since the latter do occur in actual data, the expected value is more appropriate for testing this model. Like expected volume, expected order flow volatility should be negatively related to bid-ask spreads. This is because, according to Admati and Pfleiderer (1988), market makers find order flow more tolerable in high volume periods because it accompanies high uninformed volumes and competition among informed traders makes this order flow less damaging. Unexpected order flow volatility and expected order flow volatility should be unrelated to each other. 
Both unexpected volume and unexpected order flow volatility are believed to capture deviations in the relative participation rate of informed traders and should be closely and positive aligned with each other. In some market microstructure models (e.g. Diamond and Verrecchia (1987)), the absence of informed trading activity is perceived as bad news because of restrictions on short selling. The latter does not apply here. Short selling restrictions are not believed to be a problem in the spot FX market. Therefore, in the present analysis, the level of both unexpected volume and unexpected order flow volatility are seen as indicative of the strength of the price signal. Since both unexpected volume and unexpected order flow volatility represent abnormal adverse selection risk, both should be positively linked to bid-ask spreads.

Unexpected order flow should increase price change volatility. This is because the former is inversely related to the latter by the value of $\lambda$ determined by expected order flow. Therefore, its impact on price change is larger when it rises and smaller when it falls. The association between unexpected order flow and unexpected volume means that the latter should also increase price change volatility as it rises.

This synthesis of the Admati and Pfleiderer (1988) and Easley and O'Hara (1992) models predicts that bid-ask spreads should be positively related to price change volatility. This follows because both are expected to fall as expected volume and expected order flow rise. Similarly, both are expected to rise in response to increases in unexpected volume and unexpected order flow volatility. The predicted bid-ask spread-price change volatility relationship also accords with intuition, as one expects the bid-ask spread to widen when the level of price change becomes more volatile.

As alluded to at the beginning of this section, the primary purpose of the set of hypotheses below is to explore the relationship between bid-ask spreads/price innovations and the timing of informed and uninformed trading decisions. While bid-ask spreads and price changes may be measured directly, trading volume can not easily be split into informed and uninformed. However, a number of variables that are closely associated with informed trading activity are directly measurable. These are: unexpected volume, expected order flow volatility and unexpected order flow volatility. Drawing from Easley and O'Hara (1992), unexpected volume depicts informed trading by encapsulating both its presence (positive values) and its absence (negative values). Expected order flow volatility illustrates the 
normal level of informed trading. Like unexpected volume, unexpected order flow volatility encapsulates both the presence and absence of informed trading. Expected and unexpected informed trading both contribute to the level of price change volatility. The remaining variable, expected volume, comprises trading from both informed and uninformed traders. The relationships between all six variables implied by the theory above are now encapsulated in the following fifteen hypotheses.

Hypothesis 1: The bid-ask spread is positively related to unexpected order flow volatility Hypothesis 2: The bid-ask spread is negatively related to expected order flow volatility Hypothesis 3: The bid-ask spread is positively related to unexpected volume Hypothesis 4: The bid-ask spread is negatively related to expected volume Hypothesis 5: The bid-ask spread is positively related to price change volatility Hypothesis 6: Price change volatility is positively related to unexpected order flow volatility Hypothesis 7: Price change volatility is negatively related to expected order flow volatility Hypothesis 8 : Price change volatility is positively related to unexpected volume Hypothesis 9: Price change volatility is negatively related to expected volume Hypothesis 10: Expected volume is not related to unexpected order flow volatility Hypothesis 11: Expected volume is positively related to expected order flow volatility Hypothesis 12: Expected volume is not related to unexpected volume (should hold by construction) Hypothesis 13: Unexpected volume is positively related to unexpected order flow volatility Hypothesis 14: Unexpected volume is not related to expected order flow volatility Hypothesis 15: Unexpected order flow volatility is not related to expected order flow volatility (should hold by construction)

A correlation matrix representation (see below) is used to present the results for various exchange rates. The objective here is to examine empirical evidence to test the above hypotheses. The correlation matrix approach side-steps the whole issue of causality. In addition, the matrix method enables us to evaluate all elements in this lattice of hypotheses simultaneously. If a particular relationship does not conform to that hypothesised, there are three possible explanations. First, a variable may be a poor proxy for the trading behaviour it is supposed to be linked with. The magnitude of the correlation between the three variables supposedly linked with informed trading will hopefully expose any rogue proxies for that variable. Second, the underlying behavioural premise that the theory projects may be flawed. Third, a pair of variables may be driven by an external factor in such a way that their natural relationship is overwhelmed. The pattern of relationships in the correlation 
matrix should help to explain the evidence. We only explore concurrent behaviour and not leading or lagging relationships, since this is what the above theory addresses. We compare the cases pre and post EMU to explore if and how these relationships have changed.

\section{UO EO UV EV RV}

$\begin{array}{llllll}\text { BA } & + & - & + & - & + \\ \text { RV } & + & - & + & - & \\ \text { EV } & 0 & + & 0 * & \\ \text { UV } & + & 0 & & \\ \text { EO } & 0 * & \end{array}$

Key: BA - Bid-ask spread, RV - Return (Price Change) Volatility, EV - Expected Volume, UV - Unexpected Volume, EO - Expected Order Flow Volatility, and UO - Unexpected Order Flow Volatility. * - should hold by construction

\section{$4 \quad$ Data and Methodology}

The data used for the empirical analysis are 5-minute observations sampled from a large spot FX tick database provided by EBS. This dataset has not previously been made available to academic researchers. It contains quote and trade price data for eight currency pairs from the EBS electronic inter-dealer market. The quotes data comprises the best bid and ask quote prices per second. Trade data is also time-stamped to the nearest second. No information about the size of each transaction is provided. The data consist of two sample periods with five exchange rates. The first covers 01/08/98 to 04/09/98 and consists of the currency pairs USD/DEM, USD/JPY, USD/CHF, DEM/JPY and DEM/CHF. The second covers 01/08/99 to 03/09/99 and contains data on EUR/USD, USD/JPY, USD/CHF, EUR/JPY and EUR/CHF. Each sample contains 20 days of observations. In this study, the EUR is taken to be the linear successor to the DEM on the grounds that, pre-EMU, the DEM was a pan-European vehicle currency (see Hartmann (1998)).

We chose to use 5-minute samples for four reasons. First, because some instruments are less heavily traded, 5-minute intervals capture a good representation from all instruments. Second, there is so much data for some instruments that it necessary to condense it in some way in order to extract meaningful insights. Third, data which is evenly spaced in time 
makes it easier to use conventional time series methods. Fourth, the 5-minute interval is used in many previous empirical research papers. A correlation value is computed for each pair of factors sampled at 5-minute intervals, over the full length of each sample period. Each correlation coefficient uses around 7,000 observations. Hypotheses involving the bidask spread and order flow require quotes data, and 5 exchange rates have sufficient liquidity to be used in this analysis: USD/JPY, USD/CHF, EUR(DEM)/USD, EUR(DEM)/JPY, EUR(DEM)/CHF.

The bid-ask spread and price change volatility are both calculated using the difference in log prices (e.g. see Buckle et al (1998)). Bid-ask spreads use the last bid and ask prices, from series of best quote prices, in each 5-minute interval. Price change is calculated using the last trade prices in the interval. For testing, the absolute value of price change is used as a proxy for price change volatility, which is consistent with the method proposed by Andersen, Bollerslev, Diebold and Labys (2001). The other four variables, expected and unexpected order flow, and expected and unexpected volume are in units of the number of individual spot FX transactions. The expected and unexpected components are derived from the total order flow and total volume series respectively. Total volume comprises the total sell volume over the interval plus the total buy volume. Total order flow is arrived at by subtracting the total buy from the total sell volumes. Similar to price change, the absolute value of this total order flow is used as a proxy for order flow volatility in time series analysis. Since EBS do not provide volume data, the number of trades is used as a proxy. Fortunately, EBS do provide the side of each trade.

In low frequency empirical analysis, expected volume is often derived using an ARIMA model (e.g. Hartmann (1998), Bessembinder (1994), Jorion (1996)). However, we follow an alternative approach, pioneered by Danielsson and Payne (2001). They found that using the repetitive intraday volume pattern directly, which is measured as the across-day average of volume for each time segment, worked at least as well for high frequency intraday FX data. Unexpected volume is calculated as the difference between the actual volume and this expected measure. Similarly, expected order flow volatility is computed as the across-day standard deviation of order flow per time segment. Unexpected order flow volatility is the difference between the absolute value of actual order flow and the aforementioned expected measure. It is important to note that both unexpected variables will contain both positive and negative numbers and that, for each time segment, their across-day averages will sum to 
zero. For this reason, neither of the "unexpected" variables is depicted in the figures below. Formally, the variables are defined as follows:

$s_{i, \xi, \varepsilon, d, t}=\log \left(a_{i, \xi, \varepsilon, d, t}\right)-\log \left(b_{i, \xi, \varepsilon, d, t}\right)$

Equation 6: Bid-ask spread

$\left|r_{i, \xi, \varepsilon, d, t}\right|=\left|p_{i, \xi, \varepsilon, d, t}-p_{i, \xi, \varepsilon, d, t-1}\right|$

Equation 7: Return Volatility

$E V_{i, \xi, \varepsilon, t}=\sum_{d=1}^{D} V_{i, \xi, \varepsilon, d, t} / D$

Equation 8: Expected Volume

$U V_{i, \xi, \varepsilon, d, t}=V_{i, \xi, \varepsilon, d, t}-E V_{i, \xi, \varepsilon, t}$

Equation 9: Unexpected Volume

$E O_{i, \xi, \varepsilon, t}=\sum_{d=1}^{D}\left|O_{i, \xi, \varepsilon, d, t}\right| / D$

Equation 10: Expected Order Flow Volatility

$U O_{i, \xi, \varepsilon, d, t}=\left|O_{i, \xi, \varepsilon, d, t}\right|-E O_{i, \xi, \varepsilon, t}$

Equation 11: Unexpected Order Flow Volatility

In these equations, the measures are shown with five subscripts, $i$ which represents the instrument, $\xi$ which denotes the regime, $\varepsilon$ which indicates pre-EMU or post-EMU, $d$ which represents the day and $t$ which represents the time of day (to 5-minute accuracy). 


\section{Empirical Results}

The intraday patterns for the above variables, for pre-EMU and post-EMU periods, are shown in Figures 5 to 24 . The purpose of these is to present the pattern of activity throughout the day and to directly compare the pre-EMU and post-EMU periods. In all cases, the $\mathrm{Y}$-axis intersects the $\mathrm{X}$-axis at 0 . The $\mathrm{X}$-axis shows time of day in GMT. The intraday data spans 24-hours, since spot FX is a global business.

The M-shape pattern previously documented by other FX researchers is clear in the volume and volatility figures. It is also evident in the order flow volatility figures. The bid-ask spreads display a U-shaped dip during the heavy trading part of the day, i.e. when London or New York are active. The general fall in volume, return volatility and order flow volatility, and a rise in bid-ask spreads in 1999 over 1998 is revealed in intraday detail. USD/CHF did not conform to this pattern of change. For EUR(DEM)/CHF, everything is lower in 1999, although the bid-ask spread has fallen less than the other variables.

Tables 1 to 10 present the correlation matrices, where the evidence generally provides strong support for the hypotheses laid out above. However, the most contentious hypotheses, concerning the relationship between volume and volatility are overwhelmingly rejected. It is clear from visual comparison of the intraday average patterns that expected volume and price change volatility are strongly positively correlated. The correlation matrices confirm this and reveal further that unexpected volume has an even stronger positive link to price change volatility. While this finding is broadly in line with previous empirical findings, it flatly contradicts the negative volume-volatility relationship implied by the Admati and Pfleiderer (1988) framework that we demonstrated above.

A strong negative relationship between bid-ask spreads and volume is evident in the charts. The correlation matrices reveal that expected volume is significantly negatively correlated with bid-ask spreads, confirming the asserted relationship by Admati and Pfleiderer (1988). Contrary to the expectations of Easley and O'Hara (1992), the correlation matrices show that the link between bid-ask spreads and unexpected volume is very weak in these markets. All but one of the correlation matrices exhibit the expected positive sign for the relationship between bid-ask spreads and volatility. However, all these values are low and no strong link is discernable. 
The expected relationship between order flow and volume is strongly confirmed in the data. Expected order flow volatility is very highly correlated with expected volume, which is consistent with the notion that informed traders choose to trade at the same time as uninformed traders, as Admati and Pfleiderer (1988) conjectured. However, the graphs also clearly show that order flow is not dormant in the low volume period. The relationship between the unexpected components is weaker than that of the expected components but is still positive and far from insubstantial, which indicates that order flow is not the only source of unexpected volume. There are four permutations whereby an expected part of either volume or order flow volatility could be correlated with the unexpected part of either itself or the other. As predicted, all four cross-correlations were found to have coefficients of zero for every instrument and sample period.

There is strong evidence from the spot FX market to support 10 of the 15 hypotheses $(2,4$, $6,8,10,11,12,13,14$ and 15), weak evidence or no relationship in 3 cases (1, 3 and 5) and strong contrary evidence in 2 cases ( 7 and 9). In all cases, visual comparison of the charts validates the numerical findings in the correlation matrices.

The positive relationship observed between volume and return volatility raises a serious question about the ability of private information based models to completely explain the observed intraday patterns. However, it should be remembered that the central model considered here, Admati and Pfleiderer (1988), contains an implicit assumption that the variance of the price innovation is constant. If relevant macroeconomic and company news were more likely to occur during trading hours, then this assumption would not hold. In that case, perhaps a combined model based on flow-of-news and private information might fare better. However, even then, there are two pieces of evidence which suggests that this answer falls short. The first is the empirical evidence investigated by French and Roll (1986). These data included days where the market experienced unscheduled closures. There is no reason to believe that the amount of news was any less but volatility proved much lower than the open market data led one to expect. The same point applies to Ito et al's (1998) application of French and Roll's (1986) model to the spot FX market. The second piece of contrary evidence is contained in the intraday patterns, which show how price change volatility and order flow volatility closely follow the peaks and troughs of volume over the trading day. The USD/JPY is particularly telling. After Tokyo closes and 
before New York opens, a large volume of London trading can be discerned. These are average amounts of trading over August (1998 and 1999) at this time of day. It is hard to believe that much news important for the USD/JPY occurs during this period. Yet, return volatility and order flow volatility are shown to remain high during this period. This shows that the magnitude of price change seems closely aligned with order flow and with volume, even when these occur at times when relevant news is unlikely to be released.

This close association between volume and return volatility fits particularly well with Clark's (1973) original MDH model, in which volatility in daily price change is composed of $n$ successive individual price change increments within the day, and increases as $n$ increases. The number of trades, $n$, is interpreted as a proxy for volume. Admati and Pfleiderer's (1988) negative relationship between volume and bid-ask spreads is still widely supported in the correlations and in the 24-hour spot FX intra-day patterns.

\section{Conclusions}

The finding that order flow and return volatility are strongly positively correlated undermines private information as the dominant explanation of observed intraday patterns and relationships. If order flow is driven by information then order-flow volatility and return volatility should be negatively correlated. High levels of order flow should erode return by breaking up the price impact of an individual news event and merging it with offsetting price impact from uncorrelated news events. This lowers the average absolute return and so also lowers variance. This order flow erosion insight contradicts the French and Roll (1986) conclusion, as well as that of Ito et al (1998) for the FX case, that the cause of observed excess volatility during normal trading hours must be private information.

The pattern of intraday order flow volatility, a variable hitherto unaddressed in the literature, is revealed to closely track the intraday pattern of volume. Previous empirical research had only linked order flow to price determination and path dependence. Our work reveals order flow's relationship with bid-ask spreads and return volatility, as well as volume, in the context of the spot FX market.

One of our most important findings is that there was no empirical evidence to support Easley and O'Hara's (1992) prediction that the bid-ask spread and unanticipated volume 
should be positively correlated. This implies either that unanticipated volume arises from something other than information events, or that bid-ask spreads in this market do not widen in response increased adverse selection risk. However, militating against the latter conclusion is that empirical evidence supports a central assertion of Admati and Pfleiderer (1988): that expected volume and bid-ask spreads are inversely related. The bid-ask spread does indeed narrow when volume rises. Admati and Pfleiderer (1988) say that this happens because adverse selection risk is higher in low volume periods.

If this is true, then we must look to sources other than private information as the stimuli for the observed unanticipated volumes. Existing microstructure theory considers only one rival force to private information as capable of creating order flow, namely inventory. This is normally defined as a temporary imbalance between supply and demand which a market maker is willing to hold for a short period. However, a prominent role for inventory does not make much sense given the structure of the EBS spot FX inter-dealer market. There is no evidence that any market participant in this market acts as a market-maker supplying liquidity to the other participants. No participant in this market is required to supply twoway prices. Bid-ask spreads are very small as a percentage of deal value. The main motivation for dealing on the inter-dealer market is to acquire or dispose of inventory arising from client deals. The bid-ask spreads on client deals are much wider than those in the inter-dealer market.

Buyers and sellers with different motives and/or different views co-exist in the market at the same time. Garman's (1976) seminal paper on order flow permitted demand and supply probability distributions to be identical but independent. This assumption would allow both volume and order flow to appear lumpy. However, this explanation does not obviate the need for each inventory increment to demand a price concession in order to be absorbed by the market. This simple argument could account for the observed positive order flow volatility-return volatility relationship. In addition, it is consistent with Clark's (1973) MDH. Combined, these two explanations appear to go a considerable way towards explaining the puzzle of why exchange rates are excessively volatile. 


\section{References}

Abhyankar, A.H., L.S. Copeland and W. Wong, 1995, "Liffe cycles: intraday evidence from the FT-SE 100 stock index futures market”, European Journal of Finance, 5: 123-139.

Abhyankar, A.H., D. Ghosh, E. Levin and R.J. Limmack, 1997, "Bid-ask spreads, trading volume and volatility: intra-day evidence from the London Stock Exchange”, Journal of Business Finance and Accounting, 24(3/4), 343-362.

Admati, A.R., and P. Pfleiderer, 1988, "A theory of intraday patterns: volume and price variability", Review of Financial Studies, 1(1), Spring: 3-40.

Ahn, H-J., K-H. Bae and K. Chan, 1999, "Limit orders, depth and volatility: Evidence from the Stock Exchange of Hong Kong”, Journal of Finance (forthcoming).

Andersen, T.G. and T. Bollerslev, 1997, "Intraday periodicity and volatility persistence in financial markets", Journal of Empirical Finance, 4(2-3), June: 115-158.

Andersen, T., T. Bollerslev, , F. Diebold, and P. Labys, 2001, "The distribution of realized exchange rate volatility", Journal of the American Statistical Association, 96, 42-55.

ap Gwilym, O., M. Buckle, T. Foord, and S.H. Thomas, 1996, "The intraday behaviour of European bond futures", Journal of Fixed Income, 6(2), Winter: 7-17.

Atkins, A.B., and S. Basu, 1995, "The effect of after-hours announcements on the intraday U-shaped volume pattern", Journal of Business Finance and Accounting, 22(6), Summer: 789-809.

Baillie, R.T. and T. Bollerslev, 1990, "Intraday and inter-market volatility in foreign exchange rates", Review of Economic Studies, 58: 565-585.

Becker, K.G., J.E. Finnerty and K.J. Kopecky, 1993, "Economic news and intraday volatility in international bond markets", Financial Analysts Journal, 49(5-6), May-June: 81-6, 65.

Bessembinder, H., 1994, "Bid-ask spreads in the interbank foreign exchange market", Journal of Financial Economics, 35: 317-348.

Brock, W.A., and A.W. Kleidon, 1992, "Periodic market closure and trading volume: a model of intraday bids and asks", Journal of Economic Dynamics and Control, 16(3\&4): 451-489. 
Brockman, P., and D. Y. Chung, 1998, "Inter and intra-day liquidity patterns on the Stock Exchange of Hong Kong", Journal of International Financial Markets, Institutions and Money, 8(3-4), November: 277-298.

Buckle, M., O. ap Gwilym, S.H. Thomas, and M.S. Woodhams, 1998, "Intraday empirical regularities in interest rate and equity index futures markets and the effect of macroeconomic announcements", Journal of Business, Finance and Accounting, 25(7/8), September-October: 921-944.

Chan, K., K.C. Chan and G.A. Karolyi, 1991, "Intraday volatility in the stock index and stock index futures markets", Review of Financial Studies, 4(4): 657-684.

Chan, K., Y.P. Chung and H. Johnson, 1995, "The intraday behaviour of bid-ask spreads for NYSE stocks and CBOE options", Journal of Financial and Quantitative Analysis, 30(3), September: 329-346.

Chan, K.C., W.G. Christie and P.H. Schultz, 1995, "Market structure and the intraday pattern of bid-ask spreads for NASDAQ securities", Journal of Business, 68(1), January: 35-60.

Chang, E.C., P.C. Jain and P.R. Locke, 1995, "Standard and Poor's 500 index futures volatility and price changes around the New York Stock Exchange close", Journal of Business, 68, 1: 61-84.

Cheung, Y.W., and L.K. Ng, 1990, "The dynamics of S\&P500 index and S\&P500 futures intraday price volatilities”, Review of Futures Markets, 9(2): 458-486.

Clark, P.K., 1973, “A subordinated stochastic process model with finite variance for speculative prices", Econometrica, 41:. 1149-1168.

Copeland, T., 1976, "A model asset trading under the assumption of sequential information arrival", Journal of Finance, 31: 1149-1168.

Cornell, B., 1978, "Determinants of the bid-ask spread on forward foreign exchange contracts under floating exchange rates", Journal of International Business Studies, 9: 33-41.

Daigler, R.T., 1997, "Intraday futures volatility and theories of market behaviour", Journal of Futures Markets, 17(1), February: 45-74.

Danielsson, J., and R. Payne, 2001, "Measuring and explaining liquidity on an electronic limit order book: evidence from Reuters D2000-2”, presented at European Finance Association, January, Barcelona Meetings.

DeJong F. and M.W.M. Donders, 1998, "Intraday lead-lag relationships between the futures, options and stock market”, European Finance Review, 1: 337-359. 
Diamond, D.W. and R.E. Verrecchia, 1987, "Constraints on short-selling and asset price adjustment to private information”, Journal of Financial Economics, 18: 277-311.

Ding, D.K., 1999, "The determinants of bid-ask spreads in the foreign exchange futures market: a microstructure analysis”, Journal of Futures Markets, 19(3), May: 307-324.

Docking, D.S., I.G. Kawaller and P.D. Koch, 1999, "Mid-day volatility spikes in US futures markets", Journal of Futures Markets, 19(2), April: 195-216.

Easley, D. and M. O'Hara, 1992, "Time and the process of security price adjustment", Journal of Finance, 47(2): 577-605.

Ekman, P.D., 1992, "Intraday patterns in the S\&P500 index futures market", Journal of Futures Markets, 12(4): 365-381.

Epps, T., and M. Epps, 1976, "The stochastic dependence of security price changes and transaction volumes: Implications for the mixture of distributions hypothesis", Econometrica, 44: 305-321.

Evans, M., and R. Lyons, 2002, “Order flow and exchange rate dynamics”, Journal of Political Economy, 110, 170-180.

Flood, M., and A. Rose, 1995, "Fixed exchange rates: A virtual quest for fundamentals", Journal of Monetary Economics, 36: 3-37.

Foster, F.D., and S. Viswanathan, 1993, "Variations in trading volume, return volatility and trading costs: evidence on recent price formation models", Journal of Finance, 48(1), March: 187-211.

Foucault, T., 1999, "Order flow composition and trading costs in a dynamic limit order market”, Journal of Financial Markets, 2:. 99-134.

Franses, P.H., R.van Ieperen, M. Martens and B. Menkveld, 1997, "Volatility transmission and patterns in bund futures", Journal of Financial Research, 20: $459-482$.

French, K., and R. Roll, 1986, "Stock return variances; the arrival of information and the reaction of traders", Journal of Financial Economics, 17: 5-26.

Froot, K.A., J.F. Gammill and A.F. Perold, 1990, "New trading practices and the short-run predictability of the S\&P500”, in Market Volatility and Investor Confidence, New York Stock Exchange.

Gannon, G.L., 1994, "Simultaneous volatility effects in index futures", Review of Futures Markets, 13(4): 1027-1068. 
Garman, M., 1976, "Market microstructure”, Journal of Financial Economics, 3, 257275.

Gerety, M.S. and J.H. Mulherin, 1992, “Trading halts and market activity: an analysis of volume at the open and the close", Journal of Finance, 47(5), December: $1765-1784$.

Glosten, L., 1994, "Is the electronic open limit order book inevitable?", Journal of Finance, 49: 1127-1161.

Goldstein, M., and K. Kavajecz, 2000, "Eights sixteenths and market depth: Changes in tick size and liquidity provision on the NYSE", Journal of Financial Economics, 56: 125-149.

Harris, L., 1994, "Minimum price variations, discrete bid-ask spreads and quotation sizes", Review of Financial Studies, 7, 149-178.

Harris, L., 1998, “Optimal dynamic order submission strategies in some stylised trading problems", Financial Markets, Institutions and Instruments, 7, 1-75.

Hartmann, P., 1998, "Currency Competition and Foreign Exchange Markets", Cambridge University Press.

Hasbrouck, J., and G. Sofianos, 1993, “The trades of market-makers: an analysis of NYSE specialists", Journal of Finance, 48, 1565-1593.

Hiraki, T., E.D. Maberly and N. Takezawa, 1995, "The information content of end of the day index futures returns: international evidence from the Osaka Nikkei 225 futures contract", Journal of Banking and Finance, 19(5): 921-936.

Hseih, D.A., and A.W. Kleidon, 1996, "Bid-ask spreads in foreign exchange markets: implications for models of asymmetric information”, in J.A. Frankel, G. Galli and A. Giovannini (eds), The Microstructure of Foreign Exchange Markets, University of Chicago Press: 183-206.

Ito, T. and W.L. Lin, 1992, "Lunch break and intraday volatility of stock returns", Economic Letters, 39(10, May, 1992: 85-90.

Ito, T., R. Lyons and M. Melvin, 1998, "Is there private information in the FX market? The Tokyo experiment”, Journal of Finance, 53: 1111-1130.

Jain, P.C. and G.H. Joh, 1988, “The dependence between hourly prices and trading volume", Journal of Financial and Quantitative Analysis, 23(3), 269-83.

Jennings, R., L. Starks, and J. Fellingham, 1981, “An equilibrium model of asset trading with sequential information arrival”, Journal of Finance, 36: 143-161. 
Jones, C., and M. Lipson, 2001, "Sixteenths: Direct evidence on institutional trading costs", Journal of Financial Economics, 59: 253-278.

Jorion, P., 1996, "Risk and turnover in the foreign exchange market", in J.A. Frankel, G. Galli and A. Giovannini (eds), The Microstructure of Foreign Exchange Markets, University of Chicago Press: 19-37.

Kawaller, I.G., P.D. Koch and T.W. Koch, 1990, "Intraday relationships between volatility in S\&P500 futures prices and volatility in the S\&P index", Journal of Banking and Finance, 14(2/3): 373-397.

Kofman, P. and M. Martens, 1997, "Interaction between stock markets: an analysis of the common trading hours at the London and New York Stock Exchange", Journal of International Money and Finance, 16(3): 387-414.

Kyle, A.S., 1984, "Market structure, information, futures markets and price formation", in International Agricultural Trade: Advanced Readings in Price Formation, Market Structure, and Price Instability, ed. by G.G. Storey, A. Schmitz and A.H. Sarris. Boulder and London: Westview Press, 45-64.

Kyle, A.S., 1985, “Continuous auctions and insider trading”, Econometrica, 53: 13151335.

Lee J.H. and S.C. Linn, 1994, "Intraday and overnight volatility of stock index and stock index futures returns", Review of Futures Markets, 13(1): 1-38.

Lee, C.M.C., B. Mucklow and M.J. Ready, 1993, "Spreads, depth and the impact of earnings information: an intraday analysis", Review of Financial Studies, 6(2): 345-374.

Lehmann, B.N. and D.M. Modest, 1994, "Trading and liquidity on the Tokyo Stock Exchange: a bird's eye view”, Journal of Finance, 49(3), July: 951-984.

Levin, E.J. and R.E. Wright, 1999, "Explaining the intraday variation in the bid-ask spread in competitive dealership markets: a research note", Journal of Financial Markets, 2(2), May: 179:191.

Low, A.H.W. and J. Muthuswamy, 1996, "Information flows in high frequency exchange rates", in C. Dunis (ed), Forecasting Financial Markets: Exchange Rates, Interest Rates and Asset Management, John Wiley: 3-32.

Lyons, R., 2001, “The microstructure approach to exchange rates”, MIT Press.

Ma, C.K., R.L. Peterson, and R.S. Sears, 1992, "Trading noise, adverse selection and intraday bid-ask spreads in futures markets", Journal of Futures Markets, 12(5), October: 519-538. 
Madhavan, A., M. Richardson and M. Roomans, 1997, "Why do security prices change? A transaction-level analysis of NYSE stocks", Review of Financial Studies, 10(4), Winter: 1035-1064.

Madhavan A. and S. Smidt, 1993, "An analysis of changes in specialist inventories and quotations", Journal of Finance, 48(5), December: 1595-1628.

McInish, T.H. and R.A. Wood, 1990, "An analysis of transactions data for the Toronto Stock Exchange”, Journal of Banking and Finance, 14(2/3), August: 441-458.

McInish, T.H. and R.A. Wood, 1992, "An analysis of intraday patterns in bid/ask spreads for NYSE stocks”, Journal of Finance, 47(2), June: 753-764.

Niemeyer, J. and P. Sandas, 1993, “An empirical analysis of the trading structure at the Stockholm Stock Exchange", Journal of Multinational Financial Management, 3: 63-101.

Piccinato, B., G Ballocchi and M. Dacorogna, 1998, “A closer look at the Eurofutures market: intraday statistical analysis”, Working paper, Olsen and Associates.

Stephan J.A. and R.E. Whaley, 1990, "Intraday price change and trading volume relationships in the stock and stock options markets", Journal of Finance, 45(1), March: 191-220.

Subrahmanyam, A., 1991, 1989, "Risk aversion, market liquidity and price efficiency", Review of Financial Studies, 4(3): 416-441.

Tauchen, G., and M. Pitts, 1983, "The price-variability volume relationship on speculative markets", Econometrica, 51: 485-505.

Tse, Y., 1999, "Market microstructure of FTSE 100 index futures: an intraday empirical analysis”, Journal of Futures Markets, 19(1), February: 31-58.

Wang, G.H.K., R.J. Michalski, J.V. Jordan and E.J. Moriarty, 1994, “An intraday analysis of bid-ask spreads and price volatility in the S\&P500 index futures market", Journal of Futures Markets, 14(7): 837-859.

Werner I.M. and A.W. Kleidon, 1996, "UK and US trading of British cross-listed stocks: an intraday analysis of market integration", Review of Financial Studies, 9(2), Summer: 619-664. 


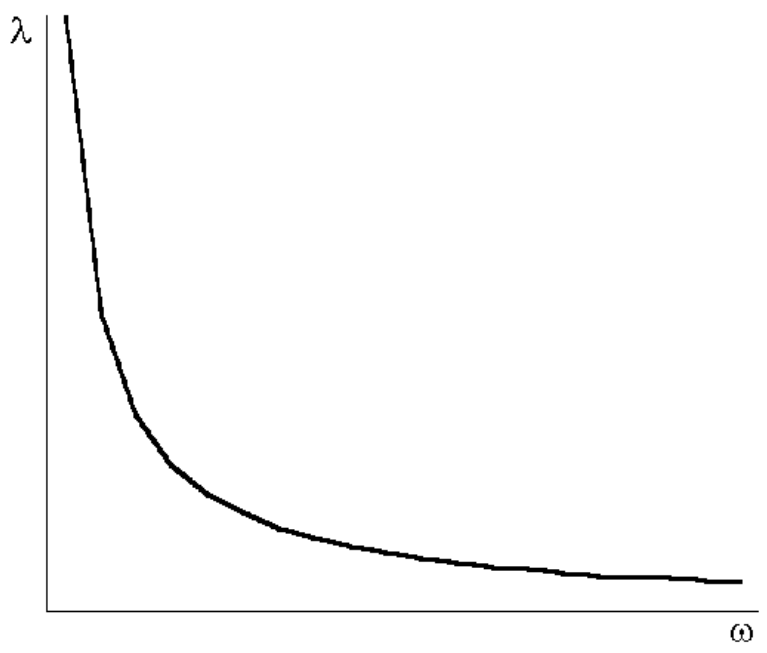

Figure 1: The relationship between $\lambda$ and $\omega$, at a given level of price informativeness

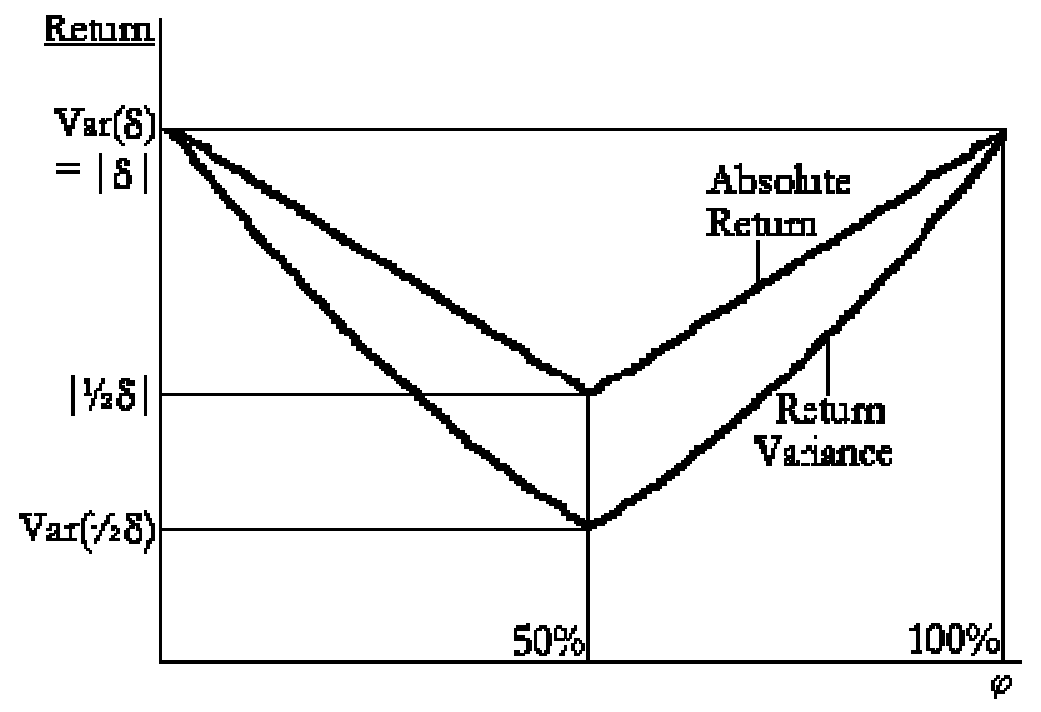

Figure 2: How informativeness of price signal ( $\varphi$ ) affects price change volatility, where $\delta=1$ 


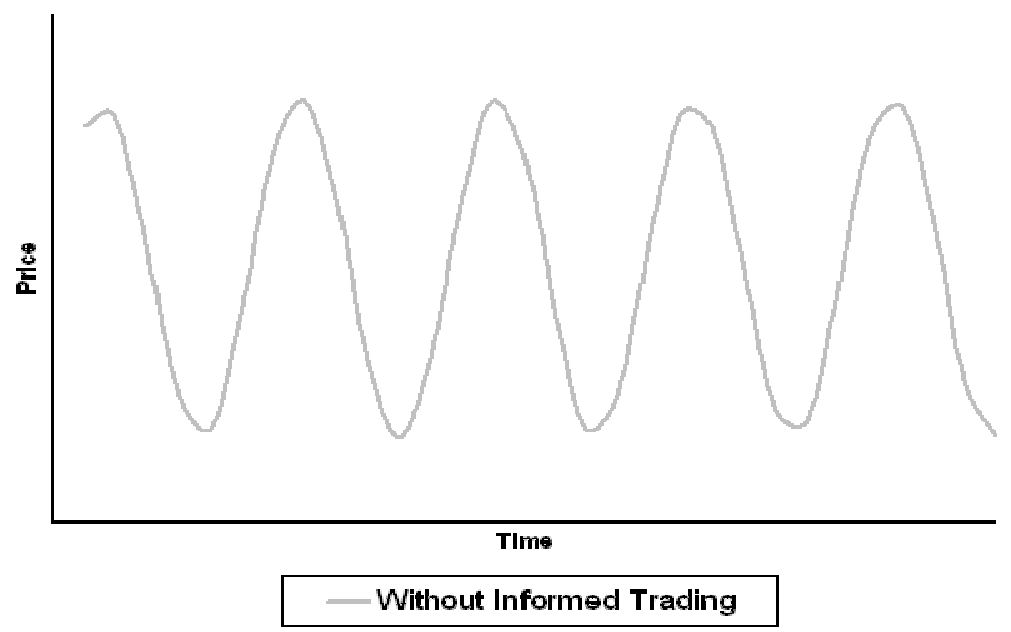

Figure 3: Price adjusts to alternate good and bad news events

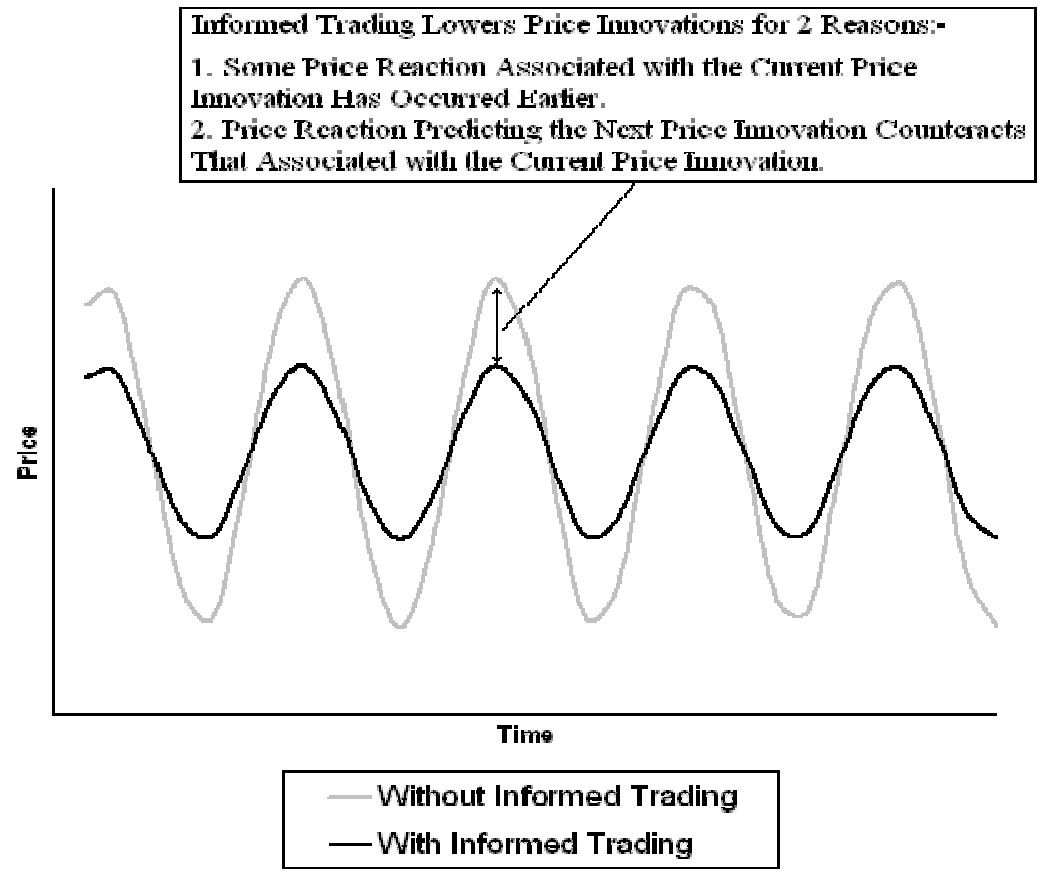

Figure 4: Informed trading disperses and mixes price reactions to news 


\section{USD/JPY}

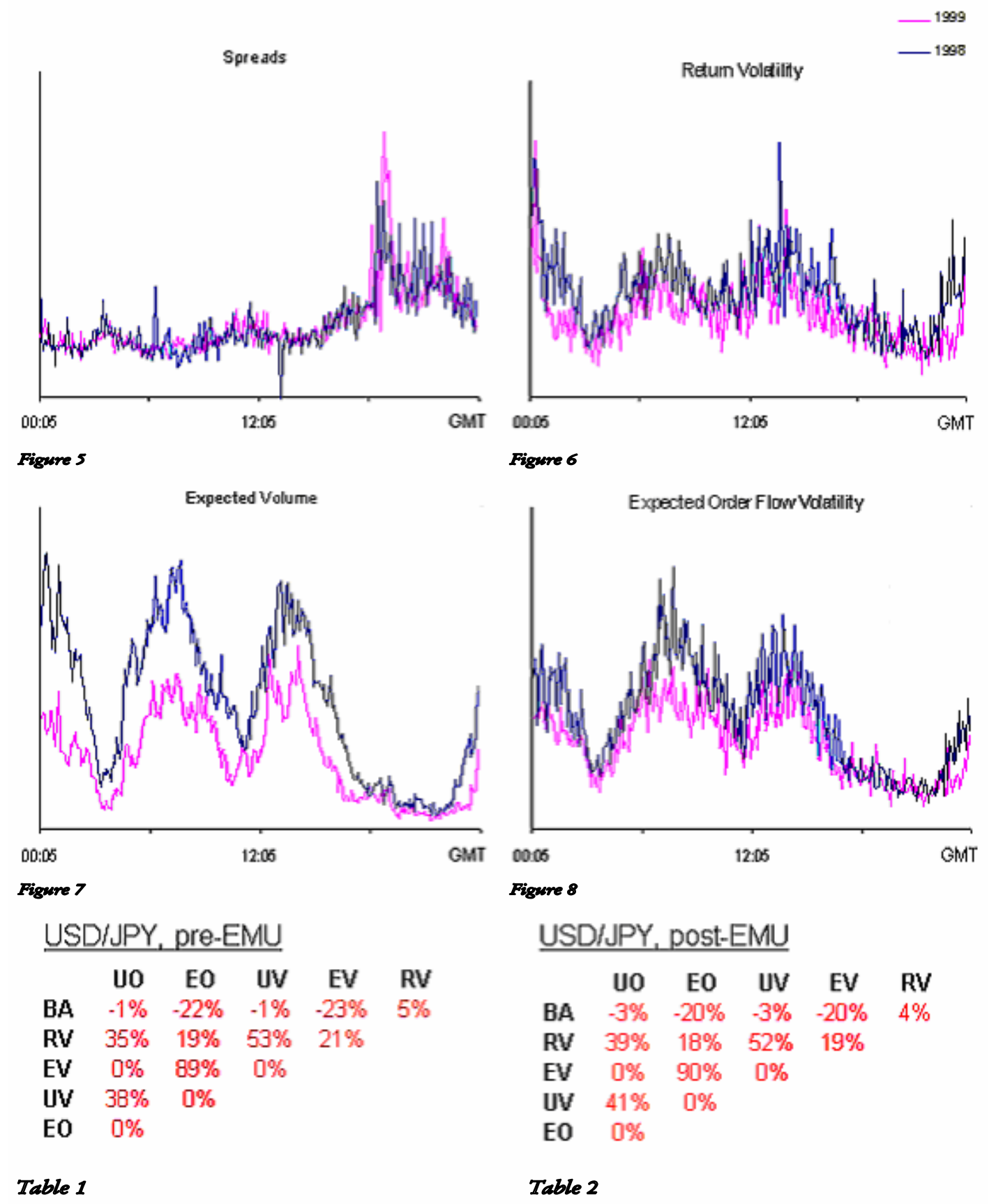




\section{USD/CHF}

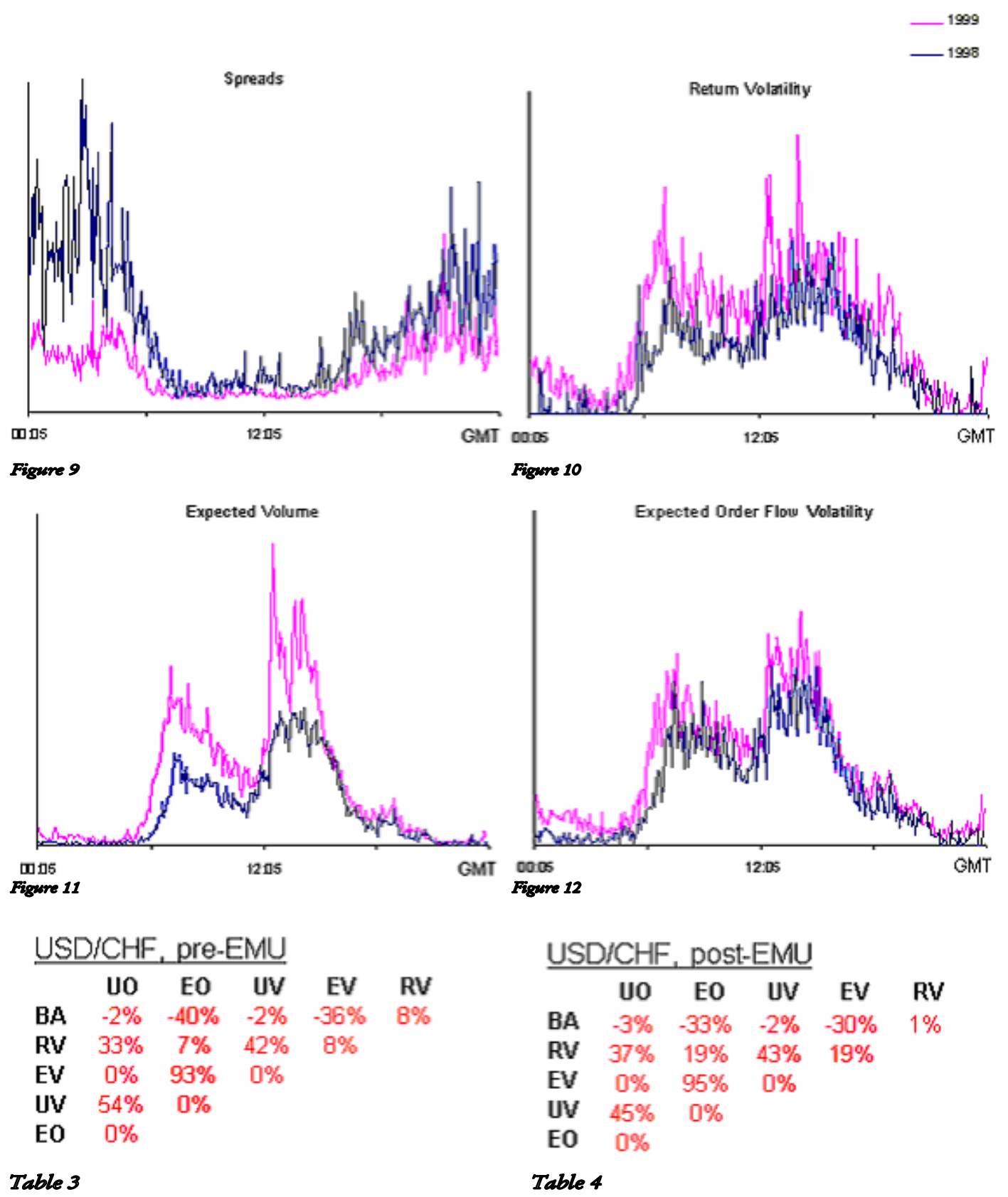




\section{EUR(DEM)/USD}
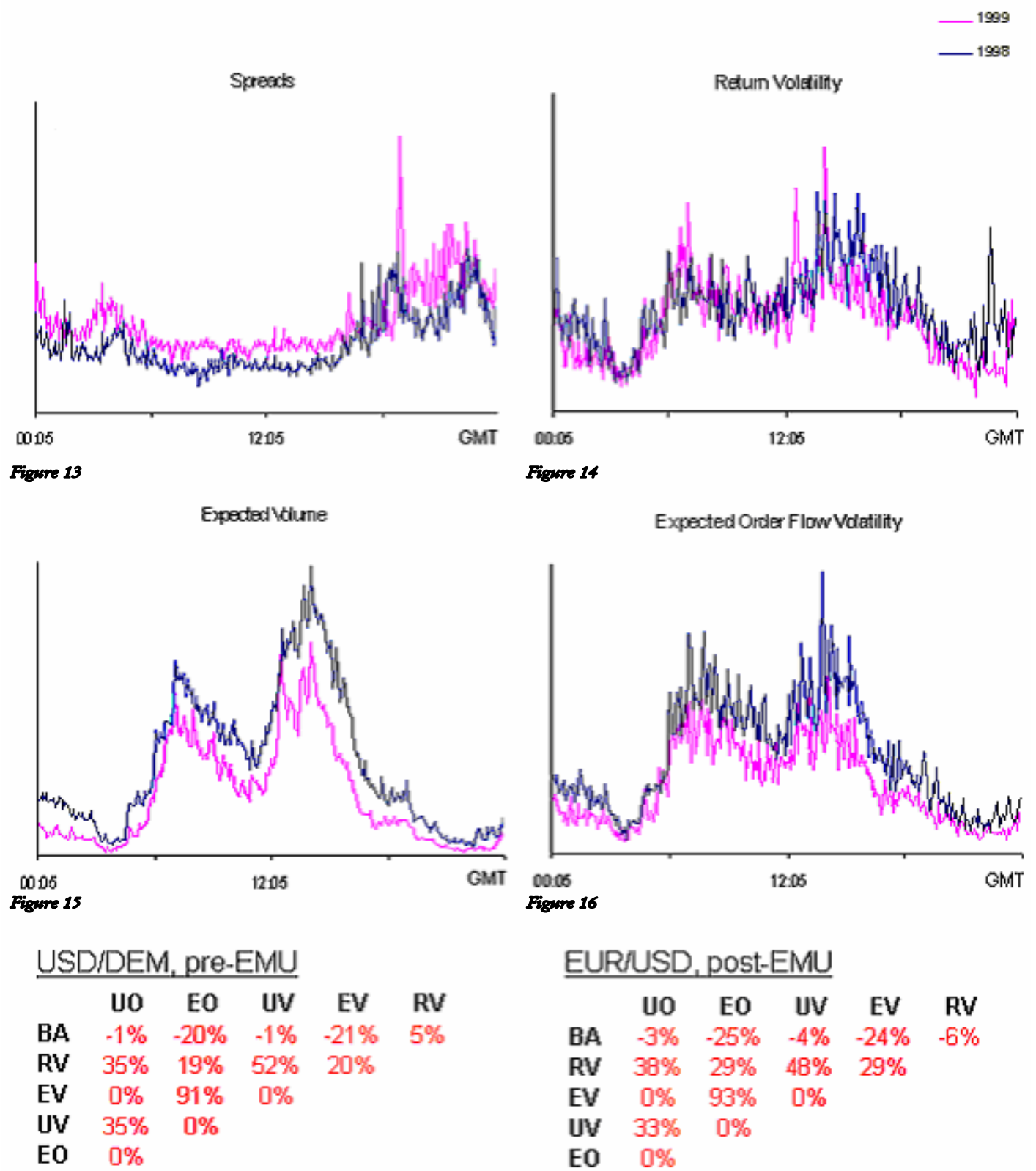

Table 5

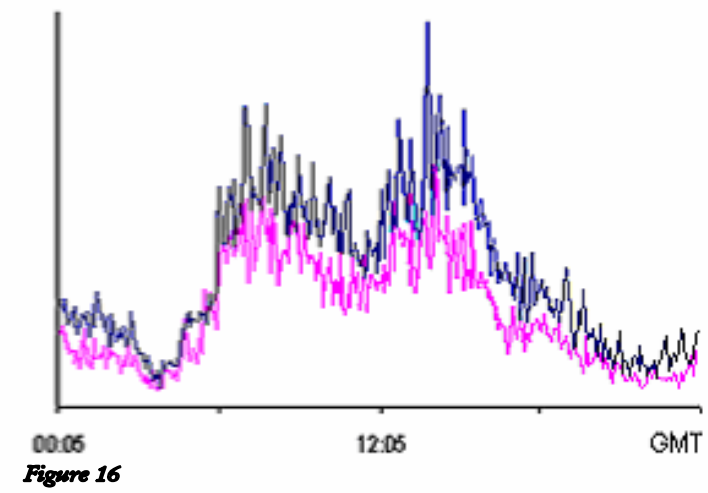

EURUSD, post-EMU

$\begin{array}{cccccc} & \text { U0 } & \text { E0 } & \text { UV } & \text { EV } & \text { RV } \\ \text { BA } & -3 \% & -25 \% & -4 \% & -24 \% & -6 \% \\ \text { RV } & 38 \% & 29 \% & 48 \% & 29 \% & \\ \text { EV } & 0 \% & 93 \% & 0 \% & & \\ \text { UV } & 33 \% & 0 \% & & & \\ \text { E0 } & 0 \% & & & & \end{array}$

Table 6 


\section{EUR(DEM)/JPY}

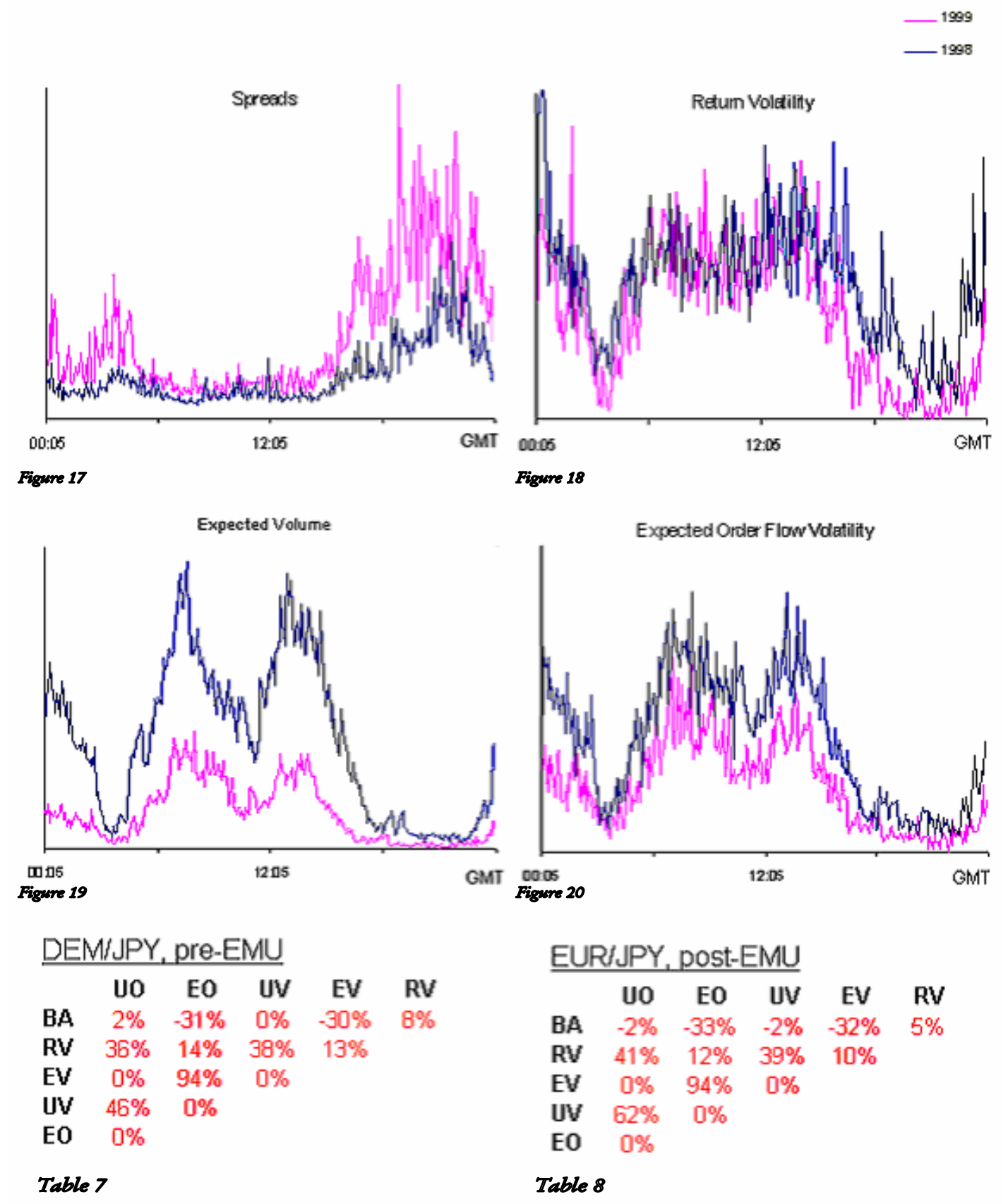




\section{EUR(DEM)/CHF}

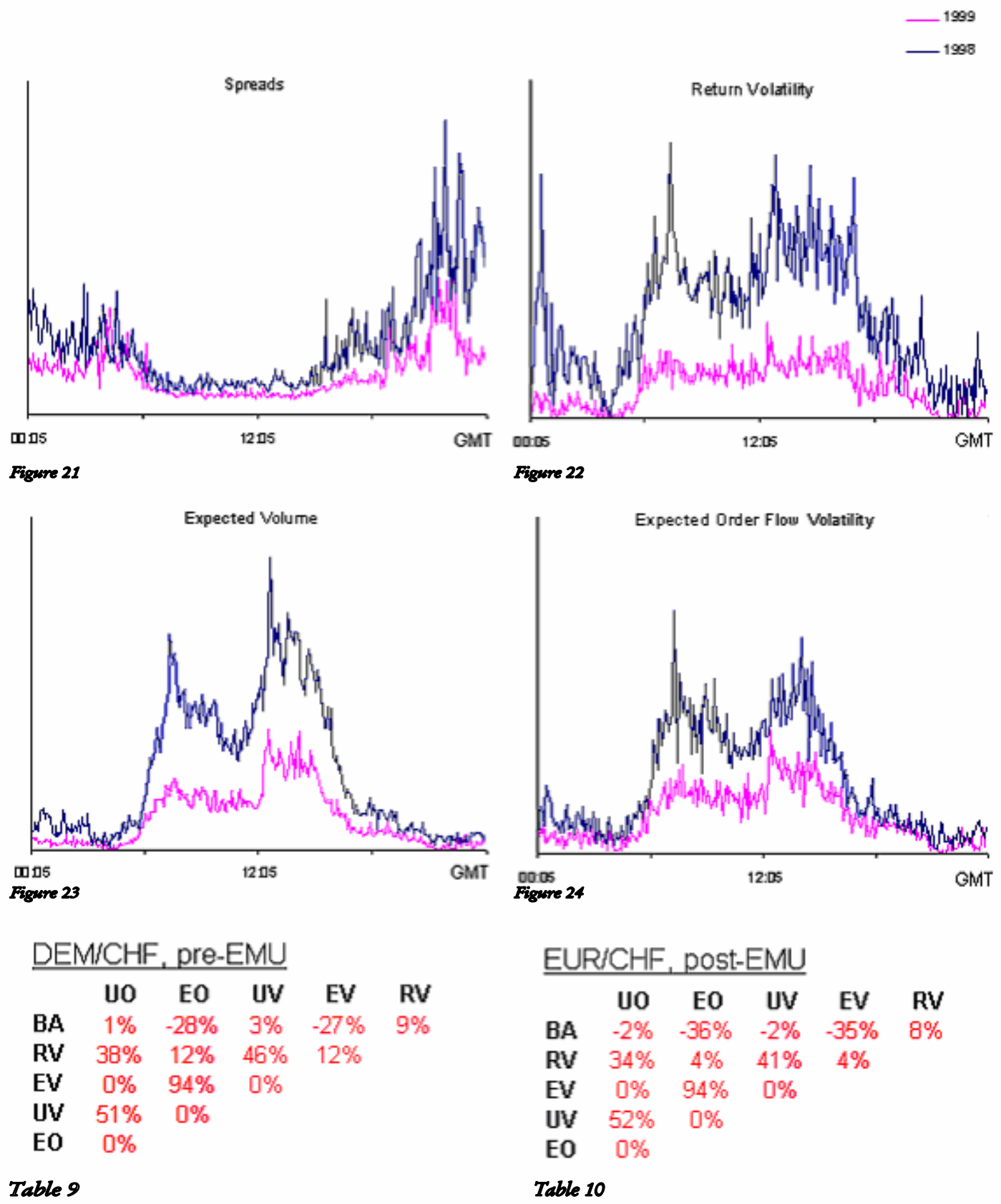

